\title{
An Analysis of Untranslatability between English and Chinese from Intercultural Perspective
}

\author{
Jianjun Wang ${ }^{1} \&$ Sunihan $^{2}$ \\ ${ }^{1}$ College of Foreign Languages, Inner Mongolia University, Hohhot, China \\ ${ }^{2}$ Office of Foreign Affairs, Inner Mongolia Museum, Hohhot, China \\ Correspondence: Jianjun Wang, College of Foreign Languages, Inner Mongolia University, Hohhot 010021, \\ China. Tel: 86-471-499-3241. E-mail: wangijpt@hotmail.com
}

\author{
Received: December 31, 2013 Accepted: February 20, 2014 Online Published: March 6, 2014 \\ doi:10.5539/elt.v7n4p119 URL: http://dx.doi.org/10.5539/elt.v7n4p119
}

\begin{abstract}
Either in the field of theoretical research of translation, or in the translation practice, there is a long dispute over the problem of translatability and untranslatability with a great number of scholars on both sides. An analysis will be made in this paper to focus on the problem of untranslatability between English and Chinese from intercultural perspective. The translation strategies to compensate the problem of untranslatability between English and Chinese will also be discussed.
\end{abstract}

Keywords: translatability, untranslatability, English, Chinese, intercultural communication

\section{Introduction}

As is known to all, in the field of both theoretical research of translation and translation practice, there is a general debate over the problem of translatability and untranslatability for a long time. Although it has been widely conceived that translation is not impossible, the translation practice has already have a history of thousands of years and played an increasingly active part in the international arena along with the overwhelming trend of globalization and the more and more frequent intercultural communication. All the cases prove that language is of course translatable to some extent, while we should not neglect the basic fact that there are still a lot of phenomena showing that untranslatability can be seen and exist in intercultural communication, especially in the translation of literary works.

This paper is aiming to analyze the phenomena of cultural untranslatability between English and Chinese in terms of its causes and compensation strategies, in the view of intercultural communication. To deeply explore the phenomena of untranslatability between English and Chinese, the first question to come forth before us is what translation, translatability and untranslatability are, on which a lot of theoretical research has been done by a great number of scholars.

\section{Translation, Translatability and Untranslatability}

\subsection{Translation}

Along with the rapid development of information technology and the overwhelming tendency of globalization, all countries have been linked up with each other closely to make the big world a small village, as a result of which, there is a growing tendency for people to communicate and exchange in various fields such as economy, culture, education, talents and so on. Having been served as a bridge in the communication among people of different races, countries, regions, and cultures, translation has been greatly contributed to the mutual development of human civilization. Generally speaking, translation is a medium of exchange and a means of communication. More exactly, it is a process of language transformation and information transfer. According to Webster's Third New International Dictionary (1971), translation is defined as a rendering from one language or representational system into another. Similar to that, The Oxford English Dictionary (1989) gives translation such a definition as the action or process of turning from one language into another. They are different kinds of descriptions of the translation process. In terms of translation of literary works, the famous Chinese writer Mao Dun (1984, p. 511) has defined translation as "to convey the artistic conception of the original works with another language". The Chinese translation theorist Huang Long $(1987$, p. 1) has defined translation from the linguistic perspective as "the replacement of textual material in one language (SL) by equivalent textual material 
in another language". Sager Jakobson has defined translation from the semiotic perspective as "an interpretation of verbal signs by means of some other language" (Shuttleworth, 1997, p. 182). Lambert has considered translation as identical to culture, on the view of culturology (Gentzler, 1993, p. 186). This definition has enlarged the cultural connotation of translation practice. The above-mentioned scholars have defined translation in terms of literature, linguistics, semiotics, culturology, after abundant theoretical research of translation.

On the basis of the above theories, we can summarize three points about translation as follows:

1) Translation is not only a transferring process between two languages, moreover, it is a transferring process between the information carried by the source language and target language, which also contains the cultural connotation, artistic connotation, aesthetic connotation and etc.

2) As a necessary means of intercultural communication, the distance between the two cultures represented by SL and TL will inevitably produce a direct influence on the translation process.

3) Taking factors such as ideology, logic pattern, religions and so forth - all into account, translation cannot achieve the absolute equivalence between SL and TL. What we try to do is just to get infinitely close to equivalence, that is, relative equivalency.

\subsection{Translatability and Untranslatability}

People have never given up trying to find out the equivalence between languages. The debate over translatability and untranslatability has never ceased, with a number of scholars on both sides. It has been mentioned by the famous Chinese scholar Liu Miqing in his Modern Translation Theories that there exists "channel for message transferring", which makes translation possible (1999, p. 99). Scholars, who cling to the idea of translatability, consider that people of different nations share a wide range of commonalities in ideology, cognition, logic and expression, all of which could help people with the practice of intercultural, interdisciplinary, international communication and exchange. Objectively speaking, no one can deny a basic fact that there have already existed a lot of translation works, which have extensively and profoundly contributed to the exchange of human civilization. Translatability is an indubitable fact, for human beings have engaged in translation practice for a quite long time.

However, the phenomena of untranslatability cannot be avoided on the other hand. According to Peter Newmark (2001, p. 7), translation is an attempted practice to replace a written or verbal message in one language by the same written or verbal message in another language, involving some kind of loss of meaning, owning to various factors. In this situation, the more meaning is lost, the less translatable it will be; the less meaning is lost, the more translatable it will be. A lot of scholars believe that there are many non-substitutable elements existing in different languages, such as its cultural tradition, social customs, emotion, and some unique words and syntactic structure, whose equivalent elements cannot be found in another language. Usually, the factors resulting in the problem of untranslatability are roughly classified into linguistic obstructions and cultural obstructions. In this sense, the loss of meaning is inevitable during the process of translation, so the absolute "faithfulness" is just an ideal that is hard to achieve, and language is untranslatable to some extent.

From the above discussion we can see that translatability is to describe the extent to which the translated version can be "loyal" to the original, while untranslatability is to witness the limit of translatability. The majority of the texts should be translatable with only a little untranslatable part. (Liu, 2000) J. C. Catford also said that the problem of translatability and untranslatability is not "dichotomy", it's more like the variate between the absolute translatability and absolute untranslatability. Translatability and untranslatability are just like the two sides of one coin, contrary but coexisting and corelated, which can thus be unified and even converted along with the development of languages and the increasing intercultural communication.

\section{Causes of Untranslatability}

Causes of untranslatability usually can be roughly divided into two categories: linguistic level and cultural level. Here we will focus on the causes of untranslatability between English and Chinese.

\subsection{Linguistic Level}

Linguistic differences are so deeply rooted that some translation practice between English and Chinese seems so hard or even impossible sometimes. We all know that English and Chinese belong to two different language families. English belongs to Indo-European language family while Chinese belongs to Sino-Tibetan language family. Being two different languages, English and Chinese differ in phonetic level, lexical level, syntactic level and rhetoric level, which can inevitably lead to the loss of message transferring, then to untranslatability.

\subsubsection{Phonetic Level}


English is intonation language while Chinese is tone language. They share nearly nothing similar in the phonetic level. There are four tones altogether in Chinese. Take Phoneme "a" as an example: ā, á, ă, à. The four tones make the pronunciation of Chinese words and sentences quite different. A special rule of tones, especially in literary works such as Chinese poetry and couplets, will enable the sentences to sound like music. Let's see some translation examples here.

寻寻受受, 冷冷清清, 凄凄惨惨戚戚。一李清照《声声慢》

This is a stanza of the poem written by Li Qingzhao, a female Chinese poet in Song Dynasty. This poem is famous for its aesthetic effect of sound, through the reduplication use of characters. It has been translated by Lin Yutang as "so dim, so dark, so dense, so dull, so damp, so dank, so dead". The translator has perfectly transferred the meaning and style of the original work, but failed in translating its "sound".

English has its own meter and rhythm too. Let's see some sentences from the famous Sonnet 18 written by William Shakespeare.

Shall I compare thee to a summer's day?

Thou art more lovely and more temperate.

Rough winds do shake the darling buds of May,

And summer's lease hath all too short a date.

The following is the translation version done by Liang Zongdai.

我怎么能够把你比作夏天?

你不独比她可爱也比她温婉。

狂风把五月宠爱的嫩荵作践,

夏天出赁的期限却未免太短。

This classic poem is written in iambic pentameter, which is quite typical in Shakespeare's poems. Although the translator has made great efforts to achieve the aesthetic effect of sound in his translation version, this unique rhythm of Shakespeare's poems cannot be reappeared because of the different sound systems of English and Chinese.

\subsubsection{Lexical Level}

It should be pointed out that lots of emphasis has been attached to hypotaxis in English while to parataxis in Chinese. There is such wide ranging of English words' meanings that we have to grasp according to the context. Just as Zhou Fangzhu (2002, p. 121) has said: "words do not have meanings: people have meanings for words." Chinese words are not that flexible as English words, and their meanings are comparatively fixed. We often find it hard to find a proper lexical equivalence in the process of translation. Take the kinship term "aunt" as an example. It may refer to 婶婶, 伯母, 姨姨, 姑姑, 阿姨 in Chinese, who are quite different from each other in kinship. The translator cannot translate immediately at the mere mention of this word, without consultation with its context.

\subsubsection{Syntactic Level}

English and Chinese are quite different in syntactic level. Some syntactic structures such as inverted sentences, passive structures, prepositional phrases and so on are often employed in English, but not often used in Chinese. In order to adapt to the idiomatic expressiveness of target language, some translation techniques may be employed to make the expressiveness correct and natural. Let's see the following example.

“Coming!" Away she skimmed over the lawn, up the path, up the stairs, across the veranda, and into the porch.

“来啦! ”她转身蹦着跳着地跑了, 越过草地, 跑上小径, 跨上台阶, 穿过凉台, 进了门廊。

This English sentence with a series of prepositional phrases is a very typical English expression. Zhang Peiji has translated this sentence by transferring the prepositions into some verbs, which are more adaptable for Chinese expression. The syntactic structures may be greatly changed while the main idea is grasped, with the use of liberal translation.

\subsubsection{Rhetoric Level}

There are featured figures of speech in different languages, such as onomatopoeia, alliteration, euphemism, antithesis, etc. in English, which may more or less lead to difficulties in translation. In Chinese, we have 对偶 (Dui Ou), 顶真(Ding Zhen), 谐音(Xie Yin) and so on. Let's see two examples of the translations of English 
antithesis and Chinese Dui Ou.

Nothing venture, nothing have.

不入虎穴, 焉得虎子。

As we know, there is no equivalent figure of speech to antithesis in Chinese, and there is no precise Chinese equivalent to the English word - antithesis either. This English sentence is a connected antithesis, which is specified by the structural balance and connects meanings in contents between the two language units. The translator hasn't translated it literally, instead, he has translated it into a Chinese proverb with the similar extending meaning in the original sentence, which is more expressive.

Let's discuss another example.

人烟寒橘柚, 秋色老梧桐。一 李白《秋登宣城谢朓北楼》

The smoke from the cottage curls,

Up around the citron trees.

And the trees of late autumn are,

On the green paulownias.

This is a stanza of Li Bai's poem, a famous Chinese poet in Tang Dynasty. It can be seen that there are only 10 Chinese characters in the Chinese version, while the English translation is wordy. This translation may succeed in presenting the images described in the poem, but fail in transferring the form beauty and artistic conception of the poem.

\subsection{Cultural Level}

With the reform and opening-up as well as the rapid economic development of China, it has been more and more frequent for Chinese people to communicate with foreigners. In this course, the communication in the cultural level is an essential part. According to Introduction to Intercultural Communication written by Hu Wenzhong (1999, p. 1), intercultural communication refers to the process of communication among people from different cultural backgrounds. Intercultural communication is aiming to promote cultural exchange and cultural transmission, and its purpose is quite similar to the purpose of translation. As a language bridge between native and non-native speakers, translation practice itself is some kind of intercultural communication activity, which can in turn contribute to improve the efficiency and effect of intercultural communication, for language, in some ways, is an important carrier of culture. It is clear that translation and intercultural communication are closely related and interactive. It has been mentioned in A New Coursebook on Chinese-English Translation (2012, p. 1) that translation is a cross-language and cross-cultural communicative activity to convert one kind of language and culture into another. So the diversity and difference of cultures are important factors leading to the problem of untranslatability.

Nida (1993, p. 37) has classified culture into five categories as social culture, ecological and geographical environment, material culture, religious culture and language culture. On the basis of this theory, we will discuss the cultural causes of untranslatability from the above-mentioned five aspects.

\subsubsection{Social Culture}

Social culture is somewhat an all-embraced concept, with a wide coverage, including historical background, values, thinking mode, etc. They all exert a profound impact on cultural differences, and thus lead to untranslatability sometimes. Every country has its own history and civilization, which make the existence of many literal quotations and idioms with historical backgrounds possible. Now "meet one's Waterloo" can be translated as 遭遇滑铁卢 literally. Only by knowing the historical background of the word Waterloo, where Napoleon was severely defeated in a battle in 1815 , can we grasp the main idea as suffering from a severe defeat. Without the historical information, this phrase would not be understood at all.

In Chinese, we often consider 狗 (dog) as a derogatory term, with so many phrases related to dogs. 狗仗人势 means being a bully with the support of someone powerful. 狗血淋头 means being abused severely. In Chinese the phrases related to dogs are almost with some negative meanings, which is quite different in English. Westerners always keep a friendly attitudes towards dogs, and there are "a lucky dog", "an old dog" and so forth in English. Sometimes, it's hard for Chinese to accept the title of "lucky dog", though it means luckiness. So in E-C translation, it would be better to avoid translating dog as 狗. Otherwise, to translate it literally may lead to misunderstanding.

\subsubsection{Ecological and Geographical Culture}


The ecological and geographical environments have a great influence on the language of one country. In this sense, one may encounter the problem of untranslatability if he has no basic geographic background knowledge.

Britain is an island country surrounded by sea, which has also been reflected in its language. For example, the extending meaning of "big fish" is an important person. "Miss the boat" means missing the best chance. These geographically featured phrases can be translated only after a good understanding of their extensive meaning.

China is an agricultural country. We have a phrase like 五谷丰登. Literally, it means the harvest of five kinds of crops, that is 稻、㯟、稷、麦、菽, five very widely planted crops in China. In C-E translation, the translator doesn't need to translate the five crops respectively. Actually, it means having a big harvest.

\subsubsection{Material Culture}

Material production also leads to the differences in cultures. "Bowler" will be associated with the Upper class by British people. "White-collar workers" and "blue-collar workers" represent mental workers and manual workers respectively. Similarly, "a bluestocking" is a symbol of female scholar. In Chinese, we have 一言九鼎 meaning the words which carries weight or authoritative words. Let's discuss. First, 鼎 (Ding) is untranslatable in C-E translation, for there's no equivalent word in English. It is an ancient cooking vessel in China, widely used by the aristocrats in Shang Dynasty. Second, this word is untranslatable literally. It is not one word and nine Dings. Instead of this, it means the words as heavy as nine Dings, which are authoritative. The above words are all representative reflection of the material culture of its language.

\subsubsection{Religious Culture}

Religion is an essential part of culture, and sometimes may become the spiritual support of one nation. Usually, British people believe in the Christianity while Chinese people believe in Buddhism. Then, words relating to religious belief come forth, such as “as poor as the church mouse" in English and 借花献佛 in Chinese. 借花 献佛 can be translated as presenting the Buddha with flowers borrowed from others literally, and its extensive meaning is to send presents provided by someone else.

It is well-known that "dragon" is the translation of Chinese character 龙. However, the "dragon" in the Holy Bible is a devil, while it is the national totem of Chinese nation, which is closely associated with auspiciousness. So 龙腾虎跃 cannot be translated as dragons rising and tigers leaping literally, because it may mislead English readers to imagine a scene of devils and monsters instead of a scene of bustling activities.

\subsubsection{Language Culture}

Another language culture that may lead to cultural untranslatability is language culture itself. To be a good translator, we need to master both SL and TL, including the sentimental color of words, the regular collocation, the proper use of synonyms, the connotation and denotation of words, etc. Take the word "heavy" for example, it can be translated into different meanings according to its collocation and context.

He is a heavy smoker.

\section{他烟抽得很凶。}

The bag is so heavy.

这个包很重。

A heavy rain.

一场大雨

"Heavy" as a very common word in English, we are quite familiar with its different meanings. However, in translation process the misunderstanding or misuse of one word may also lead to untranslatability. For this reason, a good mastery of both SL and TL as well as encyclopedia knowledge is very important for a good translator.

\section{Translation Strategies of Untranslatability}

Untranslatability is not absolute, no matter what causes lead to it. The aim of our research on untranslatability is to convert untranslatability to translatability so as to achieve mutual understanding in intercultural communication. Even sometimes, it is unconvertible, we can still take some translation strategies to compensate the loss of meanings in the process of translation from SL into TL.

\subsection{Transliteration}


Transliteration can be employed when there's no equivalent or proper word in TL, and is a major source of loanwords. This is very common in our daily life. In E-C translation, we have chocolate (巧克力), salad (沙拉), Benefit (贝玲妃), microphone (麦克风), coca-cola (可口可乐). In C-E translation, we have silk (丝), tea (茶), Kongfu (功夫), qigong (气功), taichi(太极). Their pronunciations in both SL and TL are similar. The use of transliteration will be helpful to keep the characteristics of SL.

\subsection{Literal Translation}

Literal translation is widely used in translation practice, especially to translate some words with cultural connotations. It can make contribution to reserving the cultural characteristics of SL, and to promoting cultural fusion. Let’s see some examples, cowboy (牛仔), hotdog (热狗), paper tiger (纸老虎), opening-up policy (开放 政策), Gang of Four (四人帮).

Long time no see. 好久不见。

Strike the iron while it is hot. 趁热打铁。

\subsection{Liberal Translation}

Liberal translation is usually employed to translate words relating to historical background and social customs, and requires the translator to be acquainted with the cultural connotations of SL and to combine it with TL efficiently. To convey the message of SL correctly, this method is indeed effective, though there may be no equivalent form in TL. We translate the phrase “as stupid as a goose" into 蚌得像头猪 in Chinese. Here we use the word 猪 (pig) instead of 鹅 (goose), which is adaptable to Chinese expression. The Chinese translation of “take a French leave" is 不辞而别, with the meaning of leaving without saying goodbye, instead of 像法国人 一样离开. Let's see examples of liberal translation of some proverbs.

Better late than never. 亡羊补牢, 为时不晚。

Love me and love my dog. 爱屋及乌。

\subsection{Use of Notes}

When there's no proper equivalent word in TL, sometimes the use of notes will do some help, as a form of explanation or interpretation. With the use of notes, the translator can convey some information which does not exist in TL and can make TL readers have a better understanding. Take the word “那达慕 (nadamu) " for example, if we translate it as "Mongolian sports game", the readers might be puzzled. It's better to transliterate it as "nadam", which is quite similar to its pronunciation in Mongolian, and to add a note explaining it is a traditional Mongolian sports game with wrestling, horse racing, archery competitions. From this example, we can see that the use of notes can help to keep the unique feature of language and its cultural connotation, and meanwhile to improve the quality of translation.

\section{Conclusion}

Translation is the intercultural communication between SL and TL. The translator shouldn't only keep on the linguistic level when translating, but should explore the cultural connotation of language deeply. On account of the diversity and complexity of language and culture, the problem of untranslatability actually exists. However, it's not absolute. With proper use of translation strategies, we can compensate the loss of meanings in the process of translation, and convert some factors of untranslatability into translatability. The research on the translation strategies dealing with the problem of untranslatability is extensive, which needs to be further explored.

\section{References}

Bassnett, S., \& Lefevere, A. (2001). Constructing Cultures: Essays on Literary Translation. U. K.: Multilingual Matters Ltd.

Bassnett, S. (2004). Translation Studies. Shanghai: Shanghai Foreign Language Education Press.

Bell, R. (1991). Translation and Translating. London: Longman.

Black, J., \& He, Y. (2006). Oxford Dictionary of Economics with Chinese Translation. Shanghai: Shanghai Foreign Language Education Press.

Chen, H., \& Li, Y. (2012). A New Coursebook on Chinese-English Translation. Shanghai: Shanghai Foreign Language Education Press.

Gentzler, E. (1993). Contemporary Translation Theories. London: Routledge Inc.

Gove, P. B. (1971). Webster's Third New International Dictionary. Massachusetts: G \& C Merriam Company. 
Hu, W. (1999). Introduction to Intercultural Communication. Beijing: Foreign Language Teaching and Research Press.

Huang, L. (1987). Translatology. Nanjing: Jiangsu Education Publishing House.

Liu, C. (2000). On Translatability from the Perspective of Language Function. Chinese Translators Journal, 1, 31-34.

Liu, M. (1999). Modern Translation Theories. Beijing: China Translation and Publishing Corporation.

Mao, D. (1984). Strive to Develop the Literary Translation Cause and to Improve the Translation Quality. Beijing: The Commercial Press.

Munday, J. (2001). Introducing Translation Studies: Theories and Applications. London: Routledge.

Newmark, P. (2001). Approaches to Translation. Shanghai: Shanghai Foreign Language Education Press.

Nida, E. A. (1964). Toward a Science of Translating. Leiden: E. J. Brill.

Nida, E. A. (1993). Language, Culture and Translating. Shanghai: Shanghai Foreign Language Education Press.

Shuttleworth, M., \& Cowie, M. (1997). Dictionary of Translation Studies. Manchester: ST. Jerome Publishing.

Simpson, J. A., \& Weiner, E. S. C. (1989). The Oxford English Dictionary. Oxford: Clarendon Press.

Snell-Hornby, Mary. (2001). Translation Studies: An Integrated Approach. Shanghai: Shanghai Foreign Language Education Press.

Venuti, L. (1995). The Translator's Invisibility: A History of Translation. London: Routledge.

Wang, T. (2001). Practical Course of English-Chinese \& Chinese-English Translation. Wuhan: Wuhan University Press.

Yang, D. (2009). Exploration of Culture-loaded Words. Science and Technology Innovation Herald, 14, 220-221.

Zhou, F. (2002). Principles of Translation from English into Chinese. Hefei: Anhui University Press.

\section{Copyrights}

Copyright for this article is retained by the author(s), with first publication rights granted to the journal.

This is an open-access article distributed under the terms and conditions of the Creative Commons Attribution license (http://creativecommons.org/licenses/by/3.0/). 